\title{
Risk Assessment of Oxygen Lance Burning Loss Using Bow-Tie Analysis Based on Fuzzy Theory
}

\author{
Jishuoli Li $\mathbb{D}^{D}$, Kaili Xu $\mathbb{D}^{D}$, Bingjie Fan, and Liyan Geng \\ School of Resources and Civil Engineering, Northeastern University, Shenyang, China \\ Correspondence should be addressed to Kaili Xu; xkl_safety@163.com
}

Received 12 November 2019; Accepted 20 January 2020; Published 18 February 2020

Academic Editor: Marco Pizzarelli

Copyright (c) 2020 Jishuoli Li et al. This is an open access article distributed under the Creative Commons Attribution License, which permits unrestricted use, distribution, and reproduction in any medium, provided the original work is properly cited.

Oxygen lances (OLs) are important devices used in converter steel making. However, the occurrence of OL burning loss (OLBL) failure may lead to explosion accidents. To better prevent OLBL failure, it is necessary to perform a probabilistic assessment. Bow-tie analysis based on fuzzy theory was proposed to assess OLBL, which represents a hazardous event. In this paper, fuzzy theory based on triangular fuzzy numbers (TFNs) was applied to calculate the failure data. Fuzzy fault tree analysis (FFTA) in combination with the improved similarity aggregation method (ISAM) was employed to reduce the error generated due to the subjective judgement of experts. Furthermore, a comprehensive importance analysis method was developed to rank the importance of basic events (BEs), facilitating the adoption of the corresponding safety decisions. When performing fuzzy event tree analysis (FETA), the occurrence probability of outcome events (OEs) was determined by conducting a layer of protection analysis (LOPA). Finally, safety measures were proposed based on the assessment results to achieve safe production. The results indicated that the use of bow-tie analysis is appropriate to perform qualitative and quantitative assessment. Through bow-tie analysis based on fuzzy theory, the occurrence probability of OLBL was determined to be in the interval (5.34E-02, $2.69 E-01$ ). By adding independent protective layers (IPLs), the occurrence probability of OEs caused by OLBL can be effectively reduced.

\section{Introduction}

Between 1950 to 1951, the basic oxygen furnace (BOF) was built in Linz and Donawitz. An OL was applied in the production process, and it became a commonly used device with the optimization of the BOF production process. OLs have many advantages, such as high blowing speed and realization of efficient production and satisfactory quality [1]. The Metallurgical Security Committee of China Association of Work Safety counted the number of production accidents of 36 large steel companies in 2016. There were 424 accidents and 473 casualties. The processes that were most frequently involved in these accidents included other auxiliary production, iron making, and steel making, accounting for $61.02 \%$ of the total number of accidents. The $\mathrm{OL}$ is one of the most dangerous devices in the $\mathrm{BOF}$ production process, with the common failure types including OLBL, OL falling, and OL cracking. When such failures occur, it is highly likely for the water and hightemperature molten metal to come into direct contact, leading to an explosion. For example, on April 1, 2013, a 100-tonne converter exploded in the Xinyu Iron and Steel Company in Jiangxi Province, which caused 28 injuries and 4 fatalities (the government website accident inquiry system of the State Administration of Safety Supervision and Management). This accident occurred because the residual cooling water (approximately 0.3 tonnes) in the cooling pipe of the OL flowed into the bottom of the converter, leading to contact between the water and hot slag in the bottom, thereby causing an explosion. It can be seen that in the process of metal smelting, once the high-temperature molten metal is in contact with water, the accident consequences are extremely critical $[1,2]$. However, only a few domestic and foreign scholars have investigated the risk of converter device failures, and most of them concentrated only on the methods to increase production or reduce 
energy consumption [3-6]. Therefore, it is necessary to study the causes of OL failure in converter steel making and determine the occurrence probability of the OLBL, based on which reasonable and effective measures can be proposed to prevent the occurrence of major accidents.

In recent years, safety science has been developing and many risk assessment models have been proposed [7-9]. Among the several existing risk assessment models, bow-tie is the most suitable approach to intuitively describe the cause events and possible consequences of a hazardous event. The bow-tie diagram contains a fault tree (FT) and an event tree (ET) composed of proactive and reactive elements, respectively [10]. Bow-tie analysis has been applied in several domains, for example, in the risk prediction of passenger lifts [11], risk assessment of natural gas pipelines [12], and risk assessment in the chemical industry [13]. Bow-tie analysis is a comprehensive assessment method. Using the bow-tie diagram, the causes and possible consequences of a hazardous event after a series of protective measures have been adopted can be determined. This method has been continuously improved; for example, its diagram is no longer limited to including only the FT and ET and can also be combined with the Bayesian networks to perform risk analysis $[14,15]$.

The left side of the bow-tie diagram is the FT, and the occurrence pathways and probability of a hazardous event can be determined by performing the FTA. The right side of the bow-tie diagram is the ET, and the occurrence probability of the OEs can be determined by performing the ETA. The FTA is a classic system risk assessment method that allows both qualitative and qualitative analyses. The traditional quantitative FTA requires the failure probability of BEs. However, few failure data are available with respect to the causes of OLBL, and it is difficult to determine the probability of the failure data. Moreover, the devices of a converter are constantly optimized, and the daily safety management is constantly improved; therefore, the failure probability of some BEs is constantly changing. Therefore, the use of the traditional FTA may lead to inaccurate assessment results. The fuzzy theory proposed by Khakzad et al. [16] addresses such problems and is often employed to solve the problem of uncertainty. In recent study, Yazdi et al. discussed the development and improvement of fuzzy theory [17]. Tanaka [18] was the first researcher to apply the fuzzy theory in the FTA. He used the trapezoidal fuzzy numbers (ZFNs) to represent the failure probability of $\mathrm{BEs}$ to determine the occurrence probability of the top events. The FFTA has been applied in many fields, such as engineering construction [19], process industry [20, 21], and nuclear safety [22, 23], and its reliability and superiority compared to those of the traditional FTA have been demonstrated. The failure probability of BEs in the FFTA depends on the expert judgement. To reduce the error caused by the subjective judgement, the experts are often assigned weights based on factors such as occupation, age, and knowledge level [24-26]. To make the assessment results more objective and reflect the uncertainty of the assessment results, Renjith et al. [27] used the hesitation of the experts to determine the summary results of the experts in the FFTA of the chlor-alkali industry. When a large gap is found among the experts' opinions, a similarity aggregation method (SAM) can be used to reduce the errors. This method was originally proposed by $\mathrm{Hsu}$ and Chen [28], and the premise of using this method is that the set of fuzzy numbers corresponding to the comment set between the experts must have an intersection. To eliminate this limitation, Rajakarunakaran et al. [29, 30] optimized the approach by varying degrees, which, to some extent, reduced the error caused by the large gap in the expert judgement. This review shows that the FFTA has been rapidly developed and is widely used. The use of this approach can not only solve the problem of missing failure data but also fully reflect the uncertainty of the assessment results and provide a basis for the decision making of the system [31-33].

The purpose of this paper is to propose a risk assessment model to evaluate the risk of OLBL under the condition that only partial failure data can be obtained. Part of the failure data in this study was obtained from standard reliability data sources. And the failure data which cannot be obtained from the existing data were determined by the fuzzy method based on expert judgement. In order to minimize the error of quantitative analysis, ISAM was proposed to calculate the final results of failure data. Then, bow-tie analysis was applied to make risk assessment of OLBL. A comprehensive importance analysis method based on three importance measures was proposed to determine the critical nodes of hazardous events. Meanwhile, the occurrence probability of OEs was determined by the method of LOPA. Finally, safety measures aiming at the critical nodes and OEs were proposed to reduce the risk of OLBL.

In the existing studies, the probabilistic and consequence assessment of OLBL was not performed. Therefore, in this paper, bow-tie analysis was used to assess the risk of OLBL. Section 2 introduces the methods used in the assessment process. Section 3 describes the process of probabilistic assessment based on the FFTA. Section 4 presents the assessment of the probability and consequences of OLBL, according to a case study.

\section{Methods}

This section introduces the methods used in the assessment process.

2.1. Bow-Tie. Comprehensive risk assessment is often required to be performed for high-risk events. Bow-tie is one of the commonly used risk assessment methods that analyses the accident scenarios to determine the occurrence pathways and probability of BEs and OEs [11]. Five elements are included in the bow-tie diagram, namely, the BE, FT, failure event (or hazardous event), ET, and OE. As shown in Figure 1, the FT on the left side and ET on the right side are connected through a hazardous event. The occurrence pathways and probability of the hazardous 


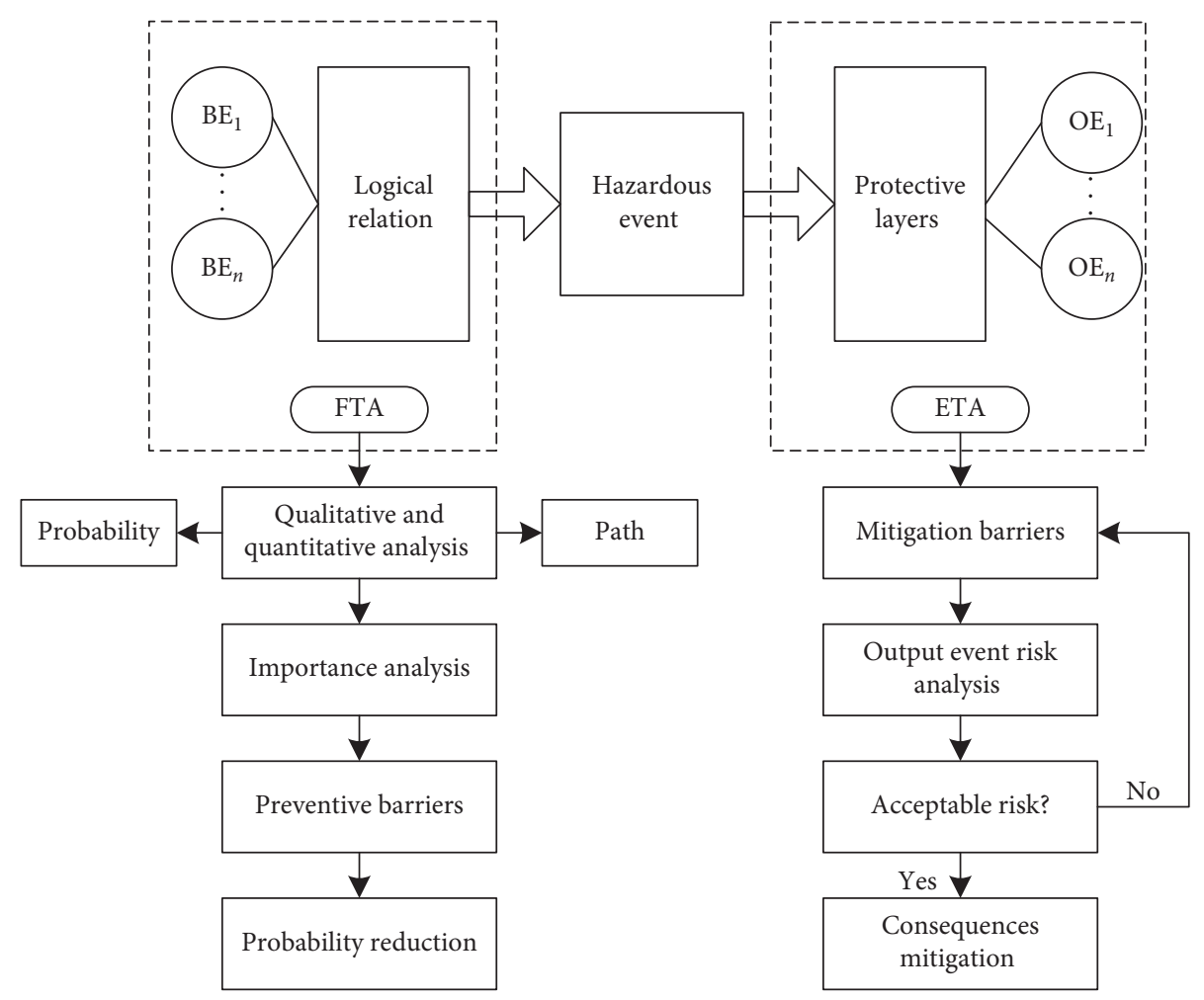

Figure 1: Bow-tie diagram.

event can be determined using the FTA. Subsequently, preventive barriers can be implemented to effectively reduce the occurrence probability of the hazardous event. The consequences of the hazardous event can be determining using the ETA, and mitigative barriers can later be introduced to effectively mitigate the consequences of such accidents [34].

2.2. FT Structure of OLBL. The OL is one of the important units in a pure oxygen top-blown converter, which includes an OL and an OL lifting device. The main process flowchart of converter steel making is shown in Figure 2. In the blowing process, the temperature in the furnace reaches up to $2000^{\circ} \mathrm{C}$. The OL endures the high-temperature furnace gas radiation in the molten pool, and it is likely to be corroded by molten metal and slag. These phenomena may lead to the leakage of OL under critical conditions. Furthermore, the explosion of the converter may occur when the molten metal in the furnace is exposed to water.

The systems directly related to the OL mainly include the oxygen and water supply system, OL transition system, and OL position control system. The OL may burn when an abnormal cooling water supply occurs owing to the failure of the water system. In addition, the OL may burn owing to the abnormal operation of the position control system. The oxygen nozzle and oxygen body are easily eroded by the molten steel when the OL position is abnormally low. The reasons for the occurrence of the OLBL were noted to correspond to the unreliability of the humans and devices, when considering the above two systems as the main research objects. After the cause of the OLBL was analyzed, the FT was built, as shown in Figure 3. The symbols and meanings of the events in the FT are listed in Table 1.

\section{Risk Assessment Process of OLBL}

3.1. FFTA. In the traditional FT quantitative analysis, the failure probability of BEs is obtained by considering the accident statistics or by performing experimental tests. However, some failure data cannot be obtained using the above methods. Many domestic and foreign scholars have discussed FFTA in detail, and it has been proved to be valid for such uncertain problem [35-39].

3.1.1. Fuzzy Theory. Fuzzy theory is a method proposed by Zadeh to solve the problem of uncertainty or fuzziness [40]. According to the recent studies, ZFNs and TFNs are simple and efficient methods to describe the uncertainty and fuzziness problems [41-43]. In addition, these values facilitate the smooth transition in the process of translating the qualitative linguistic variables of a specific failure probability into a single value. Therefore, the failure probability can be calculated by using the ZFNs and TFNs in the FFTA. For example, Tanaka first used the ZFNs to calculate the failure probability of the system [18]. Wang et al. improved the TFNs and applied them to a printed circuit board assembly system [44]. This paper considered the linguistic variables provided by the experts through the TFNs. Assuming $\left(a_{1}, a_{2}, a_{3}\right)$ is a TFN, its corresponding membership function is [45] 


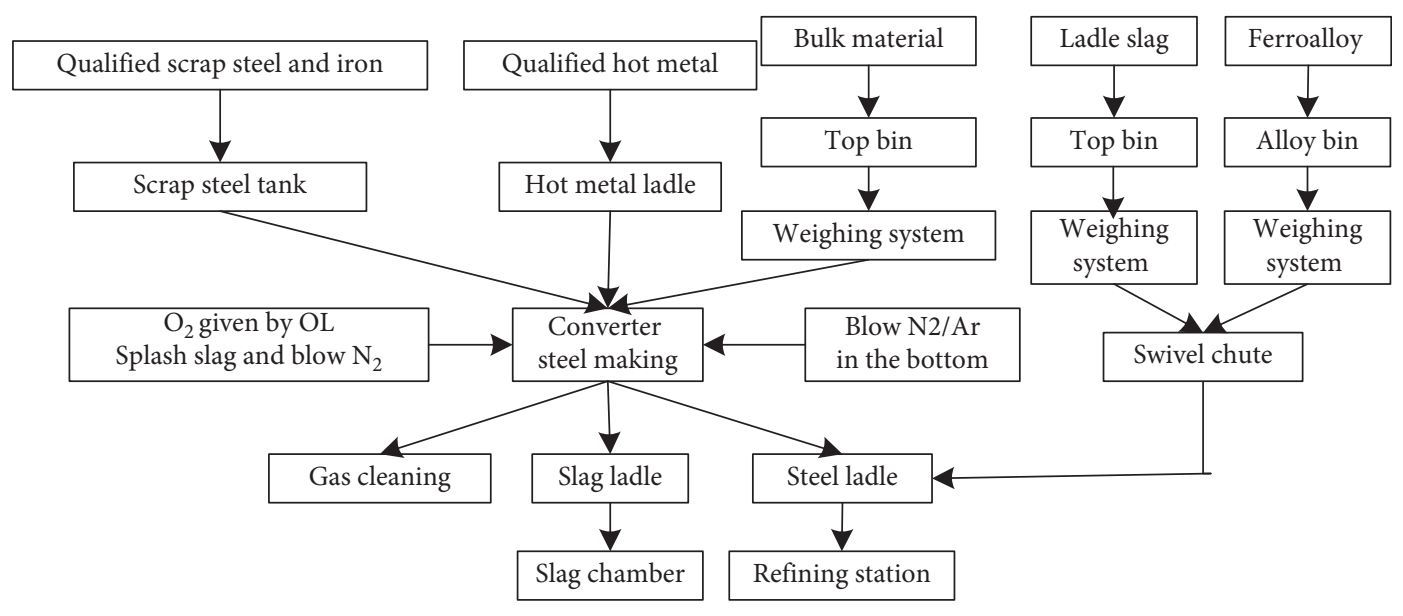

FIgURE 2: Converter steel-making process.

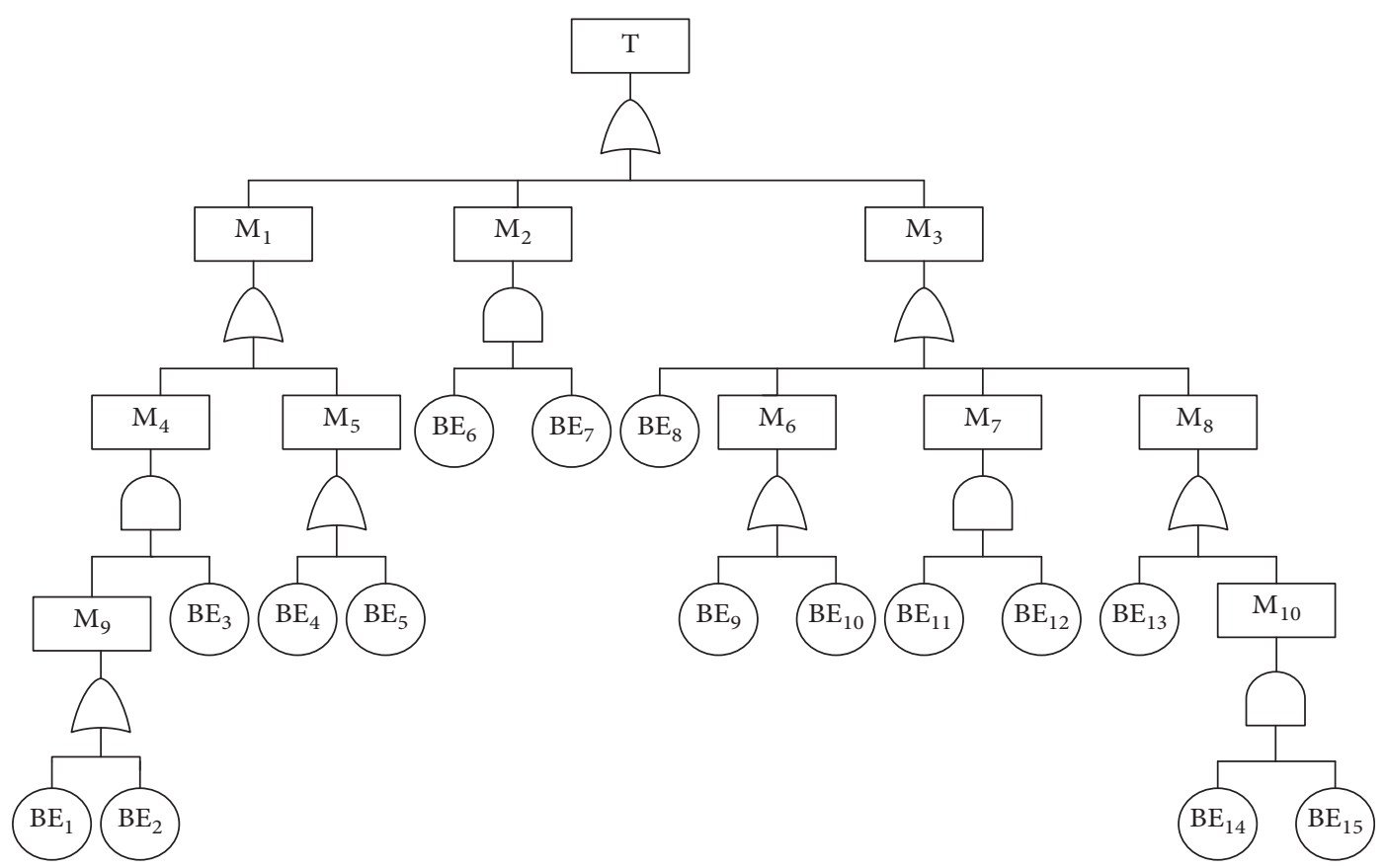

FIgURE 3: Oxygen lance burning loss FT.

$$
f_{\mu \tilde{A}}(x)= \begin{cases}0, & x \leq a_{1}, \\ \frac{\left(x-a_{1}\right)}{\left(a_{2}-a_{1}\right)}, & a_{1}<x<a_{2}, \\ \frac{\left(a_{3}-x\right)}{\left(a_{3}-a_{2}\right)}, & a_{2}<x<a_{3}, \\ 0, & x \geq a_{3},\end{cases}
$$

where $f_{\mu \tilde{A}}(x) \in[0,1]$

3.1.2. Expert Elicitation. When performing the FFTA, the experts express the possibility of the BEs with linguistic variables according to their work experience, accident cases, previous studies, and their own knowledge. The correspondence between the failure likelihood value and linguistic variables of the failure probability can be determined using many methods, such as intuition, reasoning, ranking, neural nets, genetic algorithm, and inductive reasoning [46]. Purba proved the rationality of choosing TFNs instead of ZFNs by inductive inference when evaluating the safety of a nuclear power plant. He used the segmented programme to divide the linguistic variables into 7 segments and later assigned the failure likelihood value to the corresponding TFNs, thereby representing the seven failure possibilities in a qualitative manner (Table 2, Figure 4) [47].

3.1.3. Aggregation of Experts' Opinions. Different judgement results may be obtained when the experts use qualitative 
TABLE 1: Event symbols and meanings in FT.

\begin{tabular}{lc}
\hline Symbol & Event \\
\hline $\mathrm{M}_{1}$ & Molten steel erosion \\
$\mathrm{M}_{2}$ & Nozzle aging \\
$\mathrm{M}_{3}$ & Large return water flow difference \\
$\mathrm{M}_{4}$ & Abnormal oxygen supply \\
$\mathrm{M}_{5}$ & Lower OL position \\
$\mathrm{M}_{6}$ & Cooling water flange damaged \\
$\mathrm{M}_{7}$ & Pipe blockage \\
$\mathrm{M}_{8}$ & Pipeline weld cracking \\
$\mathrm{M}_{9}$ & Larger oxygen pressure \\
$\mathrm{M}_{10}$ & Excessive internal pressure \\
$\mathrm{BE}_{1}$ & Oxygen valve failure \\
$\mathrm{BE}_{2}$ & Oxygen flange failure \\
$\mathrm{BE}_{3}$ & Oxygen pressure monitoring failure \\
$\mathrm{BE}_{4}$ & Switching oxygen timing inappropriate \\
$\mathrm{BE}_{5}$ & OL position shows abnormal \\
$\mathrm{BE}_{6}$ & Lifetime reached \\
$\mathrm{BE}_{7}$ & Nozzle not replaced in time \\
$\mathrm{BE}_{8}$ & Water valve failure \\
$\mathrm{BE}_{9}$ & Backwater flange damaged \\
$\mathrm{BE}_{10}$ & Inlet flange damaged \\
$\mathrm{BE}_{11}$ & OL pipe scaling \\
$\mathrm{BE}_{12}$ & OL pipe not cleaned in time \\
$\mathrm{BE}_{13}$ & Design defect \\
$\mathrm{BE}_{14}$ & Water vapor condensation \\
$\mathrm{BE}_{15}$ & Abnormal water circulation \\
\hline &
\end{tabular}

TABle 2: Failure possibilities, failure likelihood values, and corresponding triangular fuzzy numbers [47]].

\begin{tabular}{lcc}
\hline $\begin{array}{l}\text { Failure } \\
\text { possibilities }\end{array}$ & $\begin{array}{c}\text { Failure likelihood } \\
\text { values }\end{array}$ & $\begin{array}{c}\text { Triangular fuzzy } \\
\text { numbers }\end{array}$ \\
\hline Very low & $<1.0 E-08$ & $\mu_{\mathrm{VL}}(x)=(0.00,0.04,0.08)$ \\
Low & $1.0 E-08 \sim 1.0 E-07$ & $\mu_{\mathrm{L}}(x)=(0.07,0.13,0.19)$ \\
Reasonably low & $1.0 E-07 \sim 1.0 E-06$ & $\mu_{\mathrm{RL}}(x)=(0.17,0.27,0.37)$ \\
Moderate & $1.0 E-06 \sim 1.0 E-05$ & $\mu_{\mathrm{M}}(x)=(0.35,0.50,0.65)$ \\
Reasonably high & $1.0 E-05 \sim 1.0 E-04$ & $\mu_{\mathrm{RH}}(x)=(0.63,0.73,0.83)$ \\
High & $1.0 E-04 \sim 1.0 E-03$ & $\mu_{\mathrm{H}}(x)=(0.81,0.87,0.93)$ \\
Very high & $>1.0 E-03$ & $\mu_{\mathrm{VH}}(x)=(0.92,0.96,1.00)$ \\
\hline
\end{tabular}

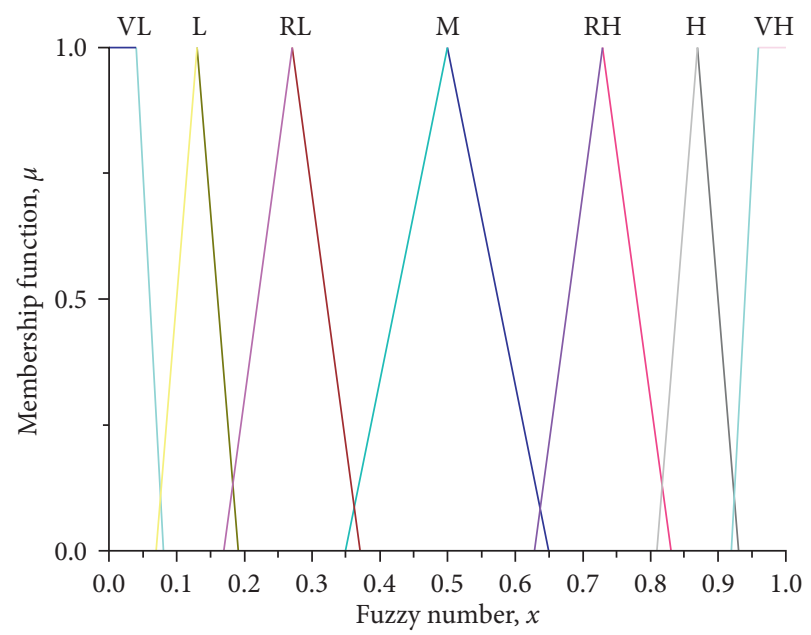

FIgURE 4: Membership function of fuzzy numbers and their corresponding failure possibilities. linguistic variables to express the possibility of BEs because of their different titles, service times, and educational backgrounds, among other factors. Many methods to aggregate the experts' opinions are available. For instance, Nurmi proposed the use of methods of voting, arithmetic averaging operation, and fuzzy preference relations [48]. Ishikawa proposed the use of the max-min Delphi method and fuzzy Delphi method [49]. Five experts were invited when performing the analysis described in this paper, including a professor, a department manager, an engineer, an operator, and a technician. The weight of each expert was based on Renjith's scoring basis [27]. The result is shown in Table 3.

Assigning a weight to the experts makes the results more objective. However, if a wide gap exists between the judgement of two experts, a large error may be incurred in the final results. To solve this problem, Hsu proposed the similarity aggregation method (SAM) [28]. However, a prerequisite must be satisfied for applying this theory; that is, the corresponding fuzzy number of the qualitative linguistic elicitation of the experts should have a common intersection at some $\alpha$-level cut. To eliminate this limitation, Rajakarunakaran et al. optimized and improved the SAM to varying degrees $[29,30]$.

In this paper, to minimize the error of the quantitative analysis, the ISAM was applied to obtain accurate results. Suppose that the corresponding fuzzy numbers of the linguistic elicitation of two experts with respect to the same $\mathrm{BE}$ are $R_{u}=\left(a_{1}, a_{2}, a_{3}\right)$ and $R_{y}=\left(b_{1}, b_{2}, b_{3}\right)$, then the similarity rate of the two experts can be denoted as

$$
S\left(R_{u}, R_{v}\right)=1-\frac{1}{3} \sum_{i=1}^{3}\left|a_{i}-b_{i}\right|,
$$

where $S\left(R_{u}, R_{y}\right) \in[0,1]$. A higher value of $S\left(R_{u}, R_{y}\right)$ corresponds to a closer judgement of the two experts. According to the judgement results of the experts on the same BE, the consistency matrix is constructed using equation (2):

$$
J=\left[\begin{array}{cccc}
1 & s_{12} & \cdots & s_{1 n} \\
s_{21} & 1 & \cdots & s_{2 n} \\
\vdots & \vdots & \ddots & \vdots \\
s_{n 1} & s_{n 2} & \cdots & 1
\end{array}\right]
$$

The average agreement degree of the $i$ th expert $\left(\mathrm{AA} e_{i}\right)$ is determined as

$$
A A\left(e_{i}\right)=\frac{1}{N-1} \sum_{\substack{u \neq v \\ v=1}}^{N} S\left(R_{u}, R_{v}\right) .
$$

The relative agreement degree of the $i$ th expert $\left(\mathrm{RA} e_{i}\right)$ is calculated as

$$
R A_{i}=\frac{A A\left(e_{i}\right)}{\sum_{u=1}^{N} A\left(e_{i}\right)} .
$$

The final weight of the experts is calculated as 
TABLE 3: Scoring results and expert weights.

\begin{tabular}{lcccccc}
\hline Expert & Title & $\begin{array}{c}\text { Service } \\
\text { time }\end{array}$ & $\begin{array}{c}\text { Education } \\
\text { background }\end{array}$ & Age & $\begin{array}{c}\text { Total } \\
\text { score }\end{array}$ & Weight \\
\hline 1 & 4 & 4 & 5 & 4 & 17 & 0.309 \\
2 & 2 & 3 & 4 & 2 & 11 & 0.2 \\
3 & 3 & 4 & 4 & 2 & 13 & 0.236 \\
4 & 1 & 2 & 2 & 1 & 6 & 0.109 \\
5 & 2 & 2 & 3 & 1 & 8 & 0.146 \\
\hline
\end{tabular}

$$
C C_{i}=\beta \cdot w_{i}+(1-\beta) \cdot R A_{i},
$$

where $\beta$ is a coefficient; $\beta=0.5$ in this paper. $\beta \in[0,1] ; \beta=0$ indicates that the assessment made by the expert is invalid. $\beta=1$ indicates that the weight of the experts is consistent with the consensus degree of the experts.

After determining the $\mathrm{CC} i$ of the experts, the fuzzy numbers corresponding to the linguistic elicitation by each expert are used to calculate the aggregation of the expert opinions of each $\mathrm{BE}$, as shown in the following equation:

$$
\mu_{B}=\sum_{i=1}^{5} C C_{i} \times \mu_{E i} \text {. }
$$

3.1.4. Defuzzification Process. The purpose of defuzzification is to transform the fuzzy numbers into a fuzzy possibility score (FPS) after the aggregation of the experts' opinions. Many methods can be used to realize the defuzzification process. For example, in the work of Lavasani et al., the centre of area defuzzification technique was used to evaluate oil and gas offshore pipelines [21]. The left and right fuzzy ranking method was used to deal with fuzzy numbers [50]. The area defuzzification technique (ADT) was used in this paper, in which the FPS was determined as

$$
\text { FPS }=\frac{1}{18}(4 a+b+d) \text {. }
$$

3.1.5. Transforming Fuzzy Possibility Score into Fuzzy Failure Rate (FFR). In the quantitative FFTA, the FPS needs to be transformed into the FFR. An algorithm was proposed by Onisawa to accomplish this process, and this method was improved and applied by many scholars [51]. The logarithmic function is defined as

$$
\mathrm{FFR}=\left\{\begin{array}{l}
\frac{1}{10^{K}}, \\
K=2.301 \times\left[\left(\frac{1-\mathrm{ADT}}{\mathrm{ADT}}\right)\right]^{1 / 3} .
\end{array}\right.
$$

3.2. Importance Analysis of BEs. The importance analysis of the BEs is a key part in the quantitative FTA, which can provide a basis for the reasonable adoption of the preventive barriers. The Fussell-Vesely (FV) value was used by Wang to calculate the importance of the BEs, and the cut sets importance (CS-I) was applied to the FFTA [25]. Vinod et al. discussed in detail three measures to calculate the importance, risk achievement worth (RAW), risk reduction worth
(RRW), and Birnbaum importance (IB) [52]. RAW indicates the importance of the systems in achieving the current safety levels. RRW indicates the maximum risk reduction of the system after improving a certain BE. Borgonovo and Apostolakis proposed a new measure to determine the importance of BEs, known as differential importance measure (DIM) analysis [53]. This approach has the advantage of additivity and can consider the effect of multiple BEs combined on the top events. Antônio proposed a measure known as the Euclidean distance (ED) [54], which was applied for the analysis of a containment cooling system. Purba proposed the $\alpha$-cut method, which was proved to be suitable for the FFTA [47]. In this paper, a comprehensive importance method based on the Bayesian importance, RAW, and RRW was developed to provide a basis for the decision making.

3.2.1. Bayesian Importance. The $\mathrm{BN}$ can be used not only to construct a clear and intuitive causal graph but also to perform probability inference [15]. When calculating the failure likelihood value of the top event, the prior probability of BEs in the BN analysis is determined by historical data or subjective judgement. In addition, the $\mathrm{BN}$ can also be used to perform probability updating. The occurrence of the top event as new evidence is used to calculate the failure probability of each $\mathrm{BE}$, which is considered as the posterior probability. The posterior probability can reflect the failure probability of BEs when an intermediate or top event occurs. Therefore, in this paper, the posterior probability in the $\mathrm{BN}$ analysis was identified as one of the measures to determine the importance of BEs [55]. This value can be determined as [56]

$$
P\left(X_{i} \mid N\right)=\frac{P\left(X_{i}\right) P\left(N \mid X_{i}\right)}{\sum_{j=1}^{n} P\left(X_{j}\right) P\left(N \mid X_{i}\right)},
$$

where $X_{i}$ is the $\mathrm{BE}$ that leads to the intermediate or top event $N, P\left(X_{i}\right)$ is the prior probability of $X_{i}, P\left(X_{i} \mid N\right)$ is the posterior probability of $X i$, and $P\left(N \mid X_{i}\right)$ is the failure probability of the top event, which denotes the likelihood function obtained from the accident precursor data.

3.2.2. Risk Achievement Worth (RAW). The RAW indicates the degree to which the risk of the system increases when the probability of a $\mathrm{BE}$ is 1 . The impact of the $\mathrm{BE}$ on the current system safety level can be reflected by calculating the RAW, as expressed in equation (11).

$$
I_{i}^{\mathrm{RAW}}=\frac{P_{T}^{B_{i}=1}}{P_{T}^{B_{i}=P_{i}}} .
$$

3.2.3. Risk Reduction Worth (RRW). RRW indicates the degree to which the risk of the system decreases when the probability of a BE is 0 . The intuitive benefits of system safety when improving the reliability of a base event can be reflected by calculating the RRW value, as expressed in the following equation: 


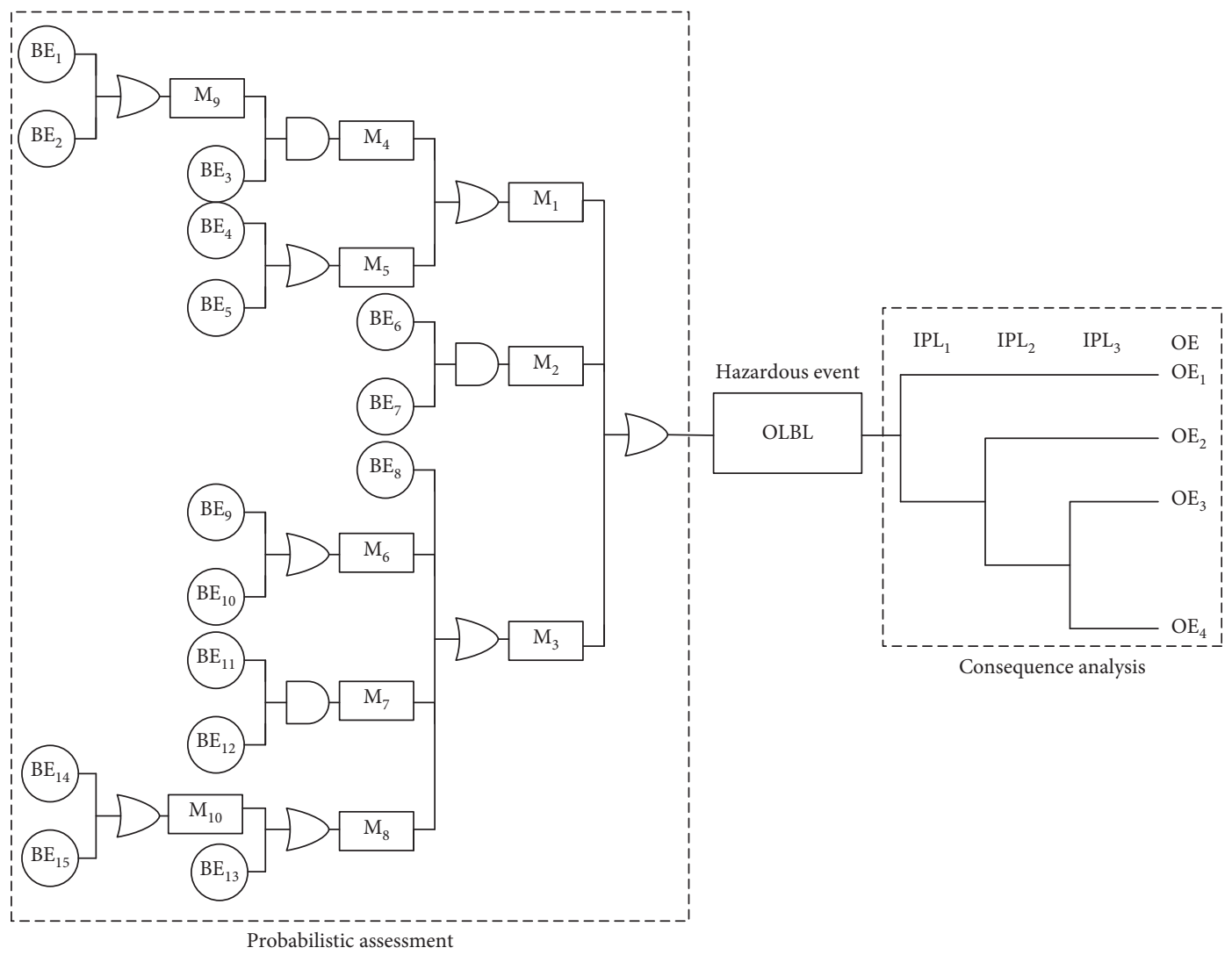

Figure 5: OLBL bow-tie model.

$$
I_{i}^{\mathrm{RRW}}=\frac{P_{T}^{B_{i}=P_{i}}}{P_{T}^{B_{i}=0}} .
$$

3.2.4. Comprehensive Importance Analysis. In this paper, a combination of the Bayesian importance, RAW, and RRW analysis methods was used to determine the final importance of BEs. It is assumed that the weight of the Bayesian importance analysis is 0.5 , and the weights of the RAW and RRW are 0.25 each. The importance of BEs can be calculated using the following equation:

$$
\left\{\begin{array}{l}
I_{i}=0.5 \times W_{i}^{\mathrm{BN}}+0.25 \times W_{i}^{\mathrm{RAW}}+0.25 W_{i}^{\mathrm{RRW}}, \\
W_{i}^{\mathrm{BN}}=\frac{I_{i}^{B N}}{\sum_{i=1}^{n} I_{i}^{B N}}, \\
W_{i}^{\mathrm{RAW}}=\frac{I_{i}^{\mathrm{RAW}}}{\sum_{i=1}^{n} I_{i}^{\mathrm{RAW}}}, \\
W_{i}^{\mathrm{RRW}}=\frac{I_{i}^{\mathrm{RRW}}}{\sum_{i=1}^{n} I_{i}^{\mathrm{RRW}}} .
\end{array}\right.
$$

3.3. Consequence Analysis. In actual production, some safety protection measures are often adopted to prevent major
TABLE 4: Failure probability of BEs (from OREDA).

\begin{tabular}{lcc}
\hline Event & Failure probability $\left(\mathrm{d}^{-1}\right)$ & Failure probability (in a year) \\
\hline $\mathrm{BE}_{1}$ & $8.16 E-06$ & $3.09 E-03$ \\
$\mathrm{BE}_{2}$ & $6.24 E-06$ & $2.36 E-03$ \\
$\mathrm{BE}_{3}$ & $4.21 E-05$ & $1.47 E-02$ \\
$\mathrm{BE}_{8}$ & $6.00 E-05$ & $2.17 E-01$ \\
$\mathrm{BE}_{9}$ & $7.24 E-05$ & $2.61 E-01$ \\
$\mathrm{BE}_{10}$ & $1.14 E-05$ & $4.12 E-02$ \\
\hline
\end{tabular}

TABLE 5: Weights of experts with respect to calculating failure probability of $X_{6}$.

\begin{tabular}{lccccccc}
\hline & \multicolumn{4}{c}{ Similarity rate } & & $\begin{array}{c}\text { Relative agreement } \\
\text { degree }\end{array}$ & Final weight \\
\hline 1 & 1 & 0.77 & 0.86 & 1 & 0.213 & 0.261 \\
1 & 1 & 0.77 & 0.86 & 1 & 0.213 & 0.207 \\
0.77 & 0.77 & 1 & 0.63 & 0.77 & 0.172 & 0.204 \\
0.86 & 0.86 & 0.63 & 1 & 0.86 & 0.188 & 0.149 \\
1 & 1 & 0.77 & 0.86 & 1 & 0.213 & 0.180 \\
\hline
\end{tabular}

accidents $[57,58]$. ETA based on LOPA was used to analyze the possible OEs in the left side of the bow-tie diagram.

The cooling water flow and temperature monitoring equipment was used as the first independent protection layer (IPL1), which enabled the staff to discover and adopt measures at the early stage of the OLBL. The methods of automatic closing of the electric valve and automatic lifting of the OL were used as the second 
TABLE 6: Failure data calculation of BEs based on fuzzy theory.

\begin{tabular}{|c|c|c|c|c|c|c|c|c|c|}
\hline \multirow[b]{2}{*}{ Event } & \multicolumn{4}{|c|}{ Expert elicitation } & \multirow[b]{2}{*}{5} & \multirow{2}{*}{$\mathrm{FFR}_{\min }\left(\mathrm{d}^{-1}\right)$} & \multirow{2}{*}{$\mathrm{FFR}_{\max }\left(\mathrm{d}^{-1}\right)$} & \multirow{2}{*}{$\mathrm{FFR}_{\mathrm{r}}\left(\mathrm{d}^{-1}\right)$} & \multirow{2}{*}{$\mathrm{FFP}_{\mathrm{r}}$ (in a year) } \\
\hline & 1 & 2 & 3 & 4 & & & & & \\
\hline $\mathrm{BE}_{4}$ & $\mathrm{RL}$ & $\mathrm{M}$ & $\mathrm{M}$ & $\mathrm{RL}$ & $\mathrm{RH}$ & $4.37 E-06$ & $3.44 E-04$ & $4.24 E-05$ & $1.53 E-01$ \\
\hline $\mathrm{BE}_{5}$ & $\mathrm{M}$ & $\mathrm{RL}$ & $\mathrm{M}$ & $\mathrm{M}$ & $\mathrm{M}$ & $4.37 E-06$ & $6.39 E-05$ & $4.47 E-05$ & $1.61 E-01$ \\
\hline $\mathrm{BE}_{6}$ & $\mathrm{RH}$ & $\mathrm{RH}$ & $\mathrm{M}$ & $\mathrm{H}$ & $\mathrm{RH}$ & $6.39 E-05$ & $7.00 E-04$ & $2.97 E-04$ & $2.38 E-01$ \\
\hline $\mathrm{BE}_{7}$ & $\mathrm{H}$ & $\mathrm{RH}$ & $\mathrm{RH}$ & $\mathrm{H}$ & $\mathrm{RH}$ & $3.44 E-04$ & $7.00 E-04$ & $4.68 E-04$ & $2.86 E-01$ \\
\hline $\mathrm{BE}_{11}$ & $\mathrm{RL}$ & $\mathrm{RL}$ & $\mathrm{M}$ & $\mathrm{M}$ & $\mathrm{M}$ & $4.37 E-06$ & $6.39 E-05$ & $2.50 E-05$ & $1.48 E-02$ \\
\hline $\mathrm{BE}_{12}$ & $\mathrm{H}$ & $\mathrm{M}$ & $\mathrm{M}$ & $\mathrm{RH}$ & $\mathrm{RH}$ & $6.39 E-05$ & $7.00 E-04$ & $2.41 E-04$ & $8.63 E-02$ \\
\hline $\mathrm{BE}_{13}$ & $\mathrm{M}$ & $\mathrm{RL}$ & $\mathrm{RL}$ & $\mathrm{L}$ & $\mathrm{RL}$ & $8.54 E-08$ & $6.39 E-05$ & $7.84 E-06$ & $2.83 E-02$ \\
\hline $\mathrm{BE}_{14}$ & $\mathrm{M}$ & $\mathrm{M}$ & $\mathrm{L}$ & $\mathrm{RL}$ & $\mathrm{L}$ & $8.54 E-08$ & $6.39 E-05$ & $9.82 E-06$ & $6.10 E-03$ \\
\hline $\mathrm{BE}_{15}$ & $\mathrm{RH}$ & $\mathrm{RH}$ & $\mathrm{H}$ & $\mathrm{M}$ & $\mathrm{M}$ & $6.39 E-05$ & $7.00 E-04$ & $2.65 E-04$ & $9.08 E-02$ \\
\hline
\end{tabular}

TABLE 7: Calculation result of importance.

\begin{tabular}{lcccr}
\hline $\mathrm{BE}$ & IBN $i$ & IRAW $i$ & IRRW $i$ & $I_{i}$ \\
\hline $\mathrm{BE}_{1}$ & $3.09 E-03$ & $1.10 E-01$ & $9.59 E-02$ & $1.97 E-02$ \\
$\mathrm{BE}_{2}$ & $2.36 E-03$ & $1.10 E-01$ & $9.59 E-02$ & $1.95 E-02$ \\
$\mathrm{BE}_{3}$ & $1.47 E-02$ & $1.01 E-01$ & $9.59 E-02$ & $2.31 E-02$ \\
$\mathrm{BE}_{4}$ & $1.52 E-01$ & 1.08 & $8.18 E-02$ & $1.00 E-01$ \\
$\mathrm{BE}_{5}$ & 1.08 & $8.11 E-02$ & $1.03 E-01$ \\
$\mathrm{BE}_{6}$ & $1.61 E-01$ & $2.36 E-01$ & $8.05 E-02$ & $9.99 E-02$ \\
$\mathrm{BE}_{7}$ & $2.37 E-01$ & $1.79 E-01$ & $8.05 E-02$ & $1.13 E-01$ \\
$\mathrm{BE}_{8}$ & $2.85 E-01$ & 1.08 & $7.60 E-02$ & $1.21 E-01$ \\
$\mathrm{BE}_{9}$ & $2.16 E-01$ & 1.07 & $7.18 E-02$ & $1.36 E-01$ \\
$\mathrm{BE}_{10}$ & $2.60 E-01$ & 1.09 & $9.21 E-02$ & $6.37 E-02$ \\
$\mathrm{BE}_{11}$ & $4.10 E-02$ & $1.76 E-01$ & $9.53 E-02$ & $2.56 E-02$ \\
$\mathrm{BE}_{12}$ & $1.48 E-02$ & $1.04 E-01$ & $9.53 E-02$ & $4.56 E-02$ \\
$\mathrm{BE}_{13}$ & $8.63 E-02$ & 1.09 & $9.33 E-02$ & $5.95 E-02$ \\
$\mathrm{BE}_{14}$ & $2.82 E-02$ & $1.84 E-01$ & $9.56 E-02$ & $2.31 E-02$ \\
$\mathrm{BE}_{15}$ & $6.09 E-03$ & $9.89 E-02$ & $9.56 E-02$ & $4.68 E-02$ \\
\hline
\end{tabular}

independent protection layer (IPL2). To prevent accidents when OLBL was not detected, the electric valve responded, the supply of cooling water automatically stopped, and the OL automatically raised. The alarm and personnel response were used as the third independent protection layer (IPL3). The alarm was issued, and immediate emergency measures were adopted to minimize the consequences of the accident when the first two IPLs failed. According to the analysis mentioned above, OLBL may cause four kinds of OEs, and the bow-tie model is as shown in Figure 5.

\section{Case Study}

The failure of the OL often occurs in steel smelting production, and among the different failure types of the OL, the probability of occurrence of the OLBL is the highest. Therefore, the steel mill needs to change the OL frequently to ensure production safety. To analyze the risk of OLBL through bow-tie analysis, first, the failure probability of OLBL was determined by performing the FFTA. Next, the consequences of the OEs caused by the hazardous event were determined by performing the ETA.

4.1. Probabilistic Assessment. The failure data of the BEs with respect to the FTA were incomplete, and some data were obtained from the OREDA [59] (Table 4). The failure probability of other nonacquirable BEs was calculated using the fuzzy theory, as mentioned above. First, the failure probability of the BEs was divided into the seven linguistic expressions of failure possibilities: VL, L, ML, M, MH, H, and $\mathrm{VH}$. Each linguistic expression corresponded to a failure rate scale, and the expressions were transformed into the corresponding fuzzy numbers (Table 2). Next, five experts from different fields were invited to provide a linguistic expression of the possibility with respect to each BE.

After the linguistic elicitation was provided by the five experts, the fuzzy numbers based on the experts' weights and relative agreement degree were determined through equations (2)-(7). Taking $X_{6}$ as an example, the linguistic elicitations expressed by the experts were $\mathrm{RH}, \mathrm{RH}, \mathrm{M}, \mathrm{H}$, and $\mathrm{RH}$, and the corresponding fuzzy numbers were $(0.63,0.73$, $0.83),(0.63,0.73,0.83),(0.35,0.5,0.65),(0.81,0.87,0.93)$, and $(0.63,0.73,0.83)$. The fuzzy number corresponding to the highest probability was $\mu_{\max }=(0.81,0.87,0.93)$ and that corresponding to the lowest probability was $\mu_{\min }=(0.35,0.5$, $0.65)$. The similarity rate of each pair of experts was determined using equation (2), and RAei was determined using equations (4) and (5). According to the expert weights listed in Table 3 and the RAei mentioned above, the final weight of each expert in the context of determining the failure probability of $X_{6}$ was determined, as shown in Table 5. 
TABLE 8: Fuzzy failure data of IPLs.

\begin{tabular}{|c|c|c|c|c|c|c|c|}
\hline \multirow{2}{*}{ Event } & \multicolumn{5}{|c|}{ Experts elicitation } & \multirow{2}{*}{$\mathrm{FFR}_{\mathrm{r}}\left(\mathrm{d}^{-1}\right)$} & \multirow{2}{*}{$\mathrm{FFP}_{\mathrm{r}}$ (in a year) } \\
\hline & 1 & 2 & 3 & 4 & 5 & & \\
\hline$\overline{\mathrm{IPL}_{1}}$ & $\mathrm{RH}$ & $\mathrm{M}$ & $\mathrm{M}$ & $\mathrm{RH}$ & $\mathrm{RH}$ & $1.92 E-04$ & $6.40 E-02$ \\
\hline $\mathrm{IPL}_{2}$ & $\mathrm{RH}$ & $\mathrm{M}$ & M & $\mathrm{RL}$ & $\mathrm{M}$ & $8.14 E-05$ & $2.71 E-02$ \\
\hline $\mathrm{IPL}_{3}$ & $\mathrm{M}$ & $\mathrm{RL}$ & M & M & M & $4.62 E-05$ & $1.54 E-02$ \\
\hline
\end{tabular}

TABle 9: Occurrence probability of OEs.

\begin{tabular}{lcc}
\hline Symbol & Event & Occurrence probability \\
\hline $\mathrm{OE}_{1}$ & Slight leakage and no effect. & $9.00 E-02$ \\
$\mathrm{OE}_{2}$ & Less water leakage and minor consequences. & $6.00 E-03$ \\
$\mathrm{OE}_{3}$ & Serious water leakage, minor casualties, and major equipment damage. & $1.64 E-04$ \\
$\mathrm{OE}_{4}$ & Serious water leakage, heavy casualties, and major equipment damage. & $2.56 E-06$ \\
\hline
\end{tabular}

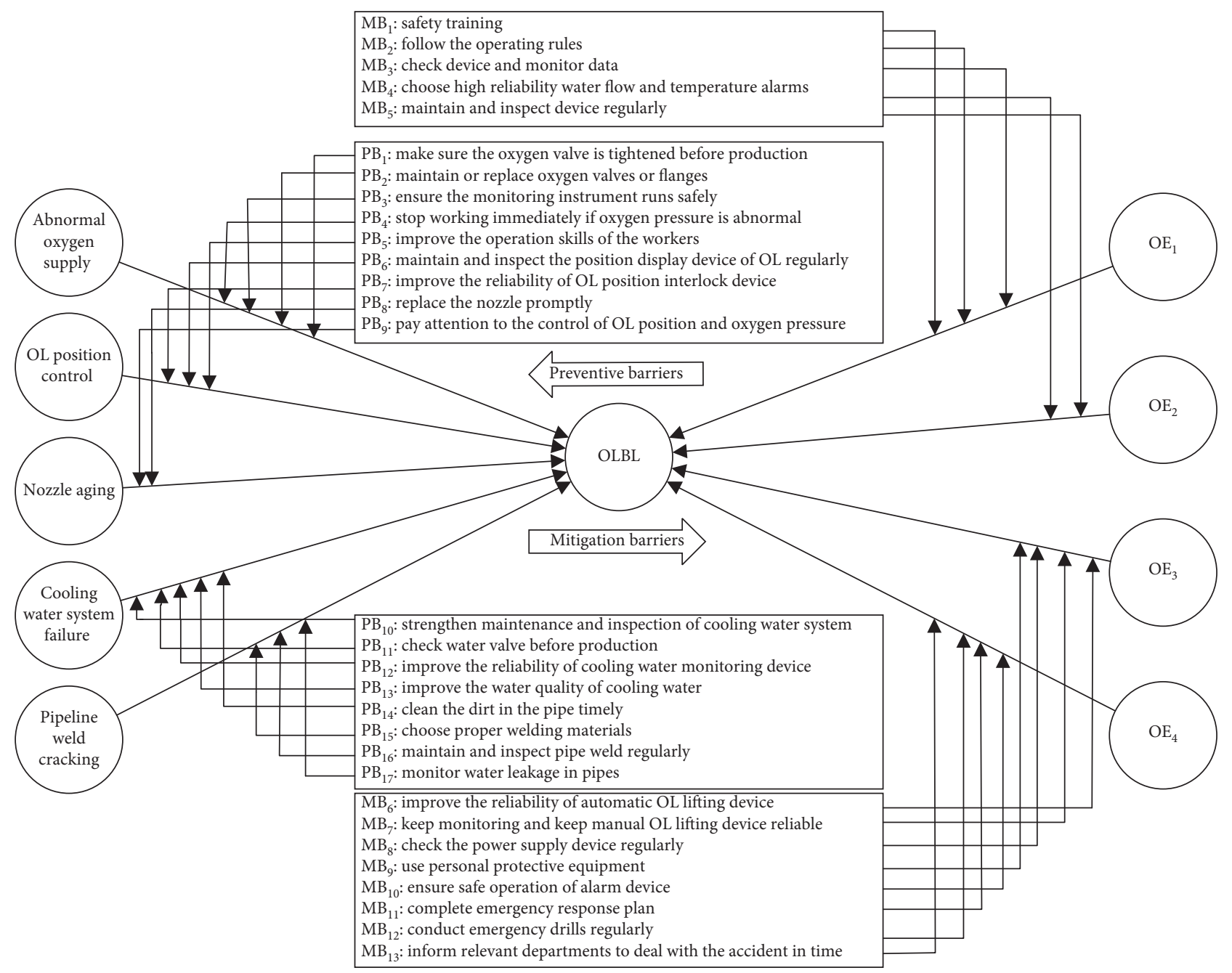

Figure 6: OLBL bow-tie diagram.

According to the final weights mentioned in Table 5, the fuzzy number of $X_{6}$ was $(0.600,0.704,0.808)$, as determined using equation (7). This fuzzy number was transformed into a crisp value known as the FPS, in this case, $\mathrm{FPS}_{6}=0.217$. Finally, the failure probability of $X_{6}$ was determined by transforming the FPS into the FFR by using equation (9), which was the most reasonable value, $\mathrm{FFR}_{\mathrm{r} 6}=2.97 E-04$. In addition, the failure probability corresponding to the maximum and minimum fuzzy numbers was calculated as $\mathrm{FFR}_{\max 6}=7 E-04$ and $\mathrm{FFR}_{\min 6}=6.39 E-05$. The calculation process of the other unobtainable BEs was the same as that for $X_{6}$. The linguistic elicitation of each expert with respect to 
each BE and the results are shown in Table 6. Correspondingly, the maximum, minimum, and most reasonable failure probabilities of OLBL were calculated as $P_{\max }=$ $2.69 E-01, P_{\min }=5.34 E-02$, and $\mathrm{P}_{\mathrm{r}}=9.59 E-02$, respectively.

4.2. Importance Analysis. Combined with the results of the posterior probability, RAW, and RRW, the final importance of the BEs was calculated using equation (13), and the result is shown in Table 7.

4.3. Consequence Analysis. The failure probability calculation method of the IPLs was consistent with that of BEs, and the results are shown in Table 8 . According to the failure probability of the hazardous event and the IPLs, the occurrence probability of the OEs was calculated (Table 9).

4.4. Safety Measures. According to the importance analysis, $\mathrm{BE}_{9}$ (backwater flange damaged) is the most important $\mathrm{BE}$ compared to other BEs. To prevent $\mathrm{BE}_{9}$, the workers need to check the flange for damage before production and monitor the incoming and return water flow during the production process. To prevent $\mathrm{BE}_{8}$ (water valve failure), the water valve must be checked and confirmed to be undamaged or tightened before production. In addition, $\mathrm{BE}_{5}, \mathrm{BE}_{6}$, and $\mathrm{BE}_{7}$, corresponding to device failure, are relatively important, and inspection, maintenance, and monitoring are required. $\mathrm{BE}_{4}$ is an operational error, and to eliminate this error, the workers need to undergo safety skills training to recognize the importance of this operation.

By studying the FT, the occurrence pathways can be ensured, and the importance of BEs can be determined. These importance values were used as a basis for adopting the preventive barriers to reduce the occurrence probability of accidents. The purpose of adopting the prevention barriers is to reduce the possibility of occurrence of the hazardous event and to effectively and reasonably prevent the occurrence of the hazardous event. Alternatively, implementing the IPLs is an effective way to reduce the risk of OEs. Therefore, the purpose of the mitigative barriers is to mitigate the consequences of OEs caused by the hazardous event. Figure 6 illustrates the preventive and mitigative barriers to ensure the system safety.

\section{Conclusion}

In the process of converter steel making, the OL is prone to damage. The occurrence of damage to an OL may lead to critical consequences if the failure is not detected in time. OLBL is a common type of failure of the OL. In the FT of OLBL, some failure data were obtained from the standard reliability data sources, and the remaining data were determined using the fuzzy theory set based on the expert judgement. Subsequently, the failure probability of OLBL was calculated, and the importance analysis of BEs was performed. Finally, the appropriate safety measures to reduce the risk of OLBL were proposed according to the assessment results.
Bow-tie analysis is one of the most effective methods to perform the probability and consequence assessments. The assessment results can provide a basis for the safe production of converter steel-making in metallurgical enterprises. Liquid steel corrosion, nozzle aging, and difference in the return flow rate were the main causes of OLBL. To reduce the occurrence probability of OLBL, the maintenance and inspection of the device, monitoring of the production process, provision of skills training for the workers, and improvement of the safety management should be performed.

Bow-tie analysis is used to determine the causes and consequences of hazardous events. In the consequence analysis, the occurrence probability of OEs was reduced by adding the IPLs. However, the occurrence probability of the minor accidents was not effectively reduced to very low. Two approaches can be used to solve this problem. First, preventive barriers can be implemented to reduce the occurrence probability of OLBL. Second, mitigative barriers can be implemented to reduce the failure probability of the IPLs.

Compared with the other assessment models, bow-tie has been validated as the best approach to realize the probability assessment and consequence assessment. To achieve the safety goal, the cause events and OEs should be considered simultaneously. According to a case study, the methods to reduce the occurrence probability of the hazardous event and OEs were illustrated. It was proved that bow-tie analysis based on fuzzy theory is an effective assessment model to guide and coordinate safe production.

In this study, the bow-tie analysis method was developed on the basis of static analysis. However, in actual production, the occurrence probability of equipment failure is closely related to the running time, maintenance, and other factors, and the occurrence probability of human error is also closely related to the service time, physical condition, and so on. Therefore, our subsequent study will focus on the risk of hazardous events and the rules of accidents based on the dynamic analysis. In addition, in the risk analysis of this study, OLBL caused by multifactor coupling was not considered. The mechanism of OLBL caused by multifactor coupling and the use of multifactor coupling to prevent accidents will be the focus of the subsequent study.

\section{Data Availability}

Our part of reliability data is from the offshore reliability data handbook (OREDA) which is published by OREDA participants. Another part of relevant data is included within the article.

\section{Conflicts of Interest}

The authors declare that they have no conflicts of interest.

\section{Authors' Contributions}

J.L. analyzed the risk assessment theory and drafted the manuscript. K.X. provided comments on the assessment model and the structure of this paper. B.F. and L.G. analyzed and calculated the reliability data. 


\section{Acknowledgments}

The authors wish to express their thanks to the National Key Research and Development Program of China (grant nos. 2018YFC0808406 and 2017YFC0805100) and the Fundamental Research Funds for the Central Universities (grant no. N180104018) for the financial support.

\section{References}

[1] Z.-F. Yuan, X. Yang, Z.-X. Lu, J.-N. Huang, Y.-F. Pan, and E.-X. Ma, "Jet behavior and metallurgical performance of innovated double-parameter oxygen lance in BOF," Journal of Iron and Steel Research International, vol. 14, no. 3, pp. 1-5, 2007.

[2] Q. Xu, K. Xu, L. Li, X. Xu, and X. Yao, "Energy release and countermeasures for sand casting explosion accidents," $\mathrm{Hu}$ man and Ecological Risk Assessment: An International Journal, vol. 8, pp. 1-13, 2019.

[3] G. Li and T. Ji, "Severe accidental water vapour explosions in a foundry in China in 2012," Journal of Loss Prevention in the Process Industries, vol. 41, pp. 55-59, 2016.

[4] J. Diao, W. Zhou, Z. Ke et al., "System assessment of recycling of steel slag in converter steelmaking," Journal of Cleaner Production, vol. 125, pp. 159-167, 2016.

[5] X. Yao, Y. Zheng, H. Zhou, K. Xu, Q. Xu, and L. Li, "Effects of biomass blending, ashing temperature and potassium addition on ash sintering behaviour during co-firing of pine sawdust with a Chinese anthracitefiring of pine sawdust with a Chinese anthracite," Renewable Energy, vol. 147, pp. 23092320, 2020.

[6] H. Guo, S. Yin, Q. Yu et al., "Iron recovery and active residue production from basic oxygen furnace (BOF) slag for supplementary cementitious materials," Resources, Conservation and Recycling, vol. 129, pp. 209-218, 2018.

[7] J. Ge, K. Xu, X. Zheng, X. Yao, Q. Xu, and B. Zhang, "The main challenges of safety science," Safety Science, vol. 118, pp. 119-125, 2019.

[8] J. J. Zhang, K. L. Xu, G. Reniers, and G. You, "Statistical analysis the characteristics of extraordinarily severe coal mine accidents (ESCMAs) in China from 1950 to 2018," Process Safety and Environmental Protection, vol. 133, pp. 332-340, 2020.

[9] J. Ge, K. Xu, C. Wu et al., "What is the object of safety science?," Safety Science, vol. 118, pp. 907-914, 2019.

[10] Q. Liu, B. Wang, Z. Wang, B. Wang, F. M. Xie, and J. Chang, "Fine production in steelmaking plants," Materials Today: Proceedings, vol. 2, pp. S348-S357, 2015.

[11] K. Mokhtari, J. Ren, C. Roberts, and J. Wang, "Application of a generic bow-tie based risk analysis framework on risk management of sea ports and offshore terminals," Journal of Hazardous Materials, vol. 192, no. 2, pp. 465-475, 2011.

[12] M. Vileiniskis and R. Remenyte-Prescott, "Quantitative risk prognostics framework based on Petri Net and Bow-Tie models," Reliability Engineering \& System Safety, vol. 165, pp. 62-73, 2017.

[13] L. Lu, W. Liang, L. Zhang, H. Zhang, Z. Lu, and J. Shan, "A comprehensive risk evaluation method for natural gas pipelines by combining a risk matrix with a bow-tie model," Journal of Natural Gas Science and Engineering, vol. 25, pp. 124-133, 2015.

[14] F. Aqlan and E. Mustafa Ali, "Integrating lean principles and fuzzy bow-tie analysis for risk assessment in chemical industry," Journal of Loss Prevention in the Process Industries, vol. 29, pp. 39-48, 2014.

[15] N. Khakzad, F. Khan, and P. Amyotte, "Dynamic safety analysis of process systems by mapping bow-tie into Bayesian network," Process Safety and Environmental Protection, vol. 91, no. 1-2, pp. 46-53, 2013.

[16] N. Khakzad, F. Khan, and P. Amyotte, "Quantitative risk analysis of offshore drilling operations: a Bayesian approach," Safety Science, vol. 57, pp. 108-117, 2013.

[17] M. Yazdi, S. Kabir, and M. Walker, "Uncertainty handling in fault tree based risk assessment: State of the art and future perspectives," Process Safety and Environmental Protection, vol. 131, pp. 89-104, 2019.

[18] H. Tanaka, L. T. Fan, F. S. Lai, and K. Toguchi, "Fault-tree analysis by fuzzy probability," IEEE Transactions on Reliability, vol. R-32, no. 5, pp. 453-457, 1983.

[19] L. Zhang, M. J. Skibniewski, X. Wu, Y. Chen, and Q. Deng, “A probabilistic approach for safety risk analysis in metro construction," Safety Science, vol. 63, no. 3, pp. 8-17, 2014.

[20] S. M. Lavasani, A. Zendegani, and M. Celik, "An extension to Fuzzy Fault Tree Analysis (FFTA) application in petrochemical process industry," Process Safety and Environmental Protection, vol. 93, no. 2, pp. 75-88, 2015.

[21] S. M. Lavasani, N. Ramzali, F. Sabzalipour, and E. Akyuz, "Utilisation of Fuzzy Fault Tree Analysis (FFTA) for quantified risk analysis of leakage in abandoned oil and natural-gas wells," Ocean Engineering, vol. 108, pp. 729-737, 2015.

[22] J. H. Purba, J. Lu, G. Q. Zhang, and D. Ruan, "An area defuzzification technique to assess nuclear event reliability data from failure possibilities," International Journal of Computational Intelligence \& Applications, vol. 11, no. 4, pp. 141-397, 2012.

[23] J. H. Purba, J. Lu, and G. Q. Zhang, "Fuzzy failure rate for nuclear power plant probabilistic safety assessment by fault tree analysis," Computational Intelligence Systems in Industrial Engineering, vol. 6, pp. 131-154, 2012.

[24] L. Shi, J. Shuai, and K. Xu, "Fuzzy fault tree assessment based on improved AHP for fire and explosion accidents for steel oil storage tanks," Journal of Hazardous Materials, vol. 278, pp. 529-538, 2014.

[25] D. Wang, P. Zhang, and L. Chen, "Fuzzy fault tree analysis for fire and explosion of crude oil tanks," Journal of Loss Prevention in the Process Industries, vol. 26, no. 6, pp. 1390-1398, 2013.

[26] C.-T. Lin and M.-J. J. Wang, "Hybrid fault tree analysis using fuzzy sets," Reliability Engineering \& System Safety, vol. 58, no. 3, pp. 205-213, 1997.

[27] V. R. Renjith, G. Madhu, V. Lakshmana Gomathi Nayagam, and A. B. Bhasi, "Two-dimensional fuzzy fault tree analysis for chlorine release from a chlor-alkali industry using expert elicitation," Journal of Hazardous Materials, vol. 183, no. 1-3, pp. 103-110, 2010.

[28] H. M. Hsu and C. T. Chen, "Aggregation of fuzzy opinions under group decision making," Fuzzy Sets and Systems, vol. 79, no. 3, pp. 279-285, 1996.

[29] S. Rajakarunakaran, A. Maniram Kumar, and V. Arumuga Prabhu, "Applications of fuzzy faulty tree analysis and expert elicitation for evaluation of risks in LPG refuelling station," Journal of Loss Prevention in the Process Industries, vol. 33, pp. 109-123, 2015.

[30] Y. E. Senol, Y. V. Aydogdu, B. Sahin, and I. Kilic, "Fault Tree Analysis of chemical cargo contamination by using fuzzy approach," Expert Systems with Applications, vol. 42, no. 12, pp. 5232-5244, 2015. 
[31] A. S. Cheliyan and S. K. Bhattacharyya, "Fuzzy fault tree analysis of oil and gas leakage in subsea production systems," Journal of Ocean Engineering and Science, vol. 3, no. 1, pp. 38-48, 2018.

[32] J. X. Yu, H. C. Chen, Y. Yu, and Z. L. Yang, "A weakest t-norm based fuzzy fault tree approach for leakage risk assessment of submarine pipeline," Journal of Loss Prevention in the Process Industries, vol. 62, p. 103968, 2019.

[33] S. Shi, B. Jiang, and X. Meng, "Assessment of gas and dust explosion in coal mines by means of fuzzy fault tree analysis," International Journal of Mining Science and Technology, vol. 28, no. 6, pp. 991-998, 2018.

[34] A. Shahriar, R. Sadiq, and S. Tesfamariam, "Risk analysis for oil \& gas pipelines: a sustainability assessment approach using fuzzy based bow-tie analysis," Journal of Loss Prevention in the Process Industries, vol. 25, no. 3, pp. 505-523, 2012.

[35] Y. H. Dong and D. T. Yu, "Estimation of failure probability of oil and gas transmission pipelines by fuzzy fault tree analysis," Journal of Loss Prevention in the Process Industries, vol. 18, no. 2, pp. 83-88, 2005.

[36] A. C. Kuzu, E. Akyuz, and O. Arslan, "Application of fuzzy fault tree analysis (FFTA) to maritime industry: a risk analysing of ship mooring operation," Ocean Engineering, vol. 179, pp. 128-134, 2019.

[37] B. Sahin, "Consistency control and expert consistency prioritization for FFTA by using extent analysis method of trapezoidal FAHP," Applied Soft Computing, vol. 56, pp. 4654, 2017.

[38] G. J. Hu, H. Phan, R. Ouache, H. Gandhi, K. Hewage, and R. Sadiq, "Fuzzy fault tree analysis of hydraulic fracturing flowback water storage failure," Journal of Natural Gas Science and Engineering, vol. 72, 2019.

[39] P. Badida, Y. Balasubramaniam, and J. Jayaprakash, "Risk evaluation of oil and natural gas pipelines due to natural hazards using fuzzy fault tree analysis," Journal of Natural Gas Science and Engineering, vol. 66, pp. 284-292, 2019.

[40] L. A. Zadeh, "Fuzzy sets," Information and Control, vol. 8, no. 3, pp. 338-353, 1965.

[41] F. Jaderi, Z. Z. Ibrahim, and M. R. Zahiri, "Criticality analysis of petrochemical assets using risk based maintenance and the fuzzy inference system," Process Safety and Environmental Protection, vol. 121, pp. 312-325, 2019.

[42] R. He, X. Li, G. Chen, Y. Wang, S. Jiang, and C. Zhi, "A quantitative risk analysis model considering uncertain information," Process Safety and Environmental Protection, vol. 118, pp. 361-370, 2018.

[43] X. Li, G. Chen, S. Jiang, R. He, C. Xu, and H. Zhu, "Developing a dynamic model for risk analysis under uncertainty: case of third-party damage on subsea pipelines," Journal of Loss Prevention in the Process Industries, vol. 54, pp. 289-302, 2018.

[44] J.-Q. Wang, R. Nie, H.-Y. Zhang, and X.-H. Chen, "New operators on triangular intuitionistic fuzzy numbers and their applications in system fault analysis," Information Sciences, vol. 251, pp. 79-95, 2013.

[45] L. X. Wang, A Course in Fuzzy System and Control, Prentice Hall PTR, Upper Saddle River, NJ, USA, 1997.

[46] T. J. Ross, "Development of membership functions," in Fuzzy Logic with Engineering Applications, pp. 178-211, John Wiley \& Sons, West Sussex, England, 2nd edition, 2004.

[47] J. H. Purba, "Fuzzy probability on reliability study of nuclear power plant probabilistic safety assessment: a review," Progress in Nuclear Energy, vol. 76, pp. 73-80, 2014.
[48] H. Nurmi, "Approaches to collective decision making with fuzzy preference relations," Fuzzy Sets and Systems, vol. 6, no. 3, pp. 249-259, 1981.

[49] A. Ishikawa, M. Amagasa, T. Shiga, G. Tomizawa, R. Tatsuta, and H. Mieno, "The max-min Delphi method and fuzzy Delphi method via fuzzy integration," Fuzzy Sets and Systems, vol. 55, no. 3, pp. 241-253, 1993.

[50] S. J. Chen and C. L. Hwang, "Fuzzy Multiple Attribute Decisionmaking Methods and Applications, Springer, Berlin, Germany, 1992.

[51] T. Onisawa, "An approach to human reliability in manmachine systems using error possibility," Fuzzy Sets and Systems, vol. 27, no. 2, pp. 87-103, 1988.

[52] G. Vinod, H. S. Kushwaha, A. K. Verma, and A. Srividya, "Importance measures in ranking piping components for risk informed in-service inspection," Reliability Engineering \& System Safety, vol. 80, no. 2, pp. 107-113, 2003.

[53] E. Borgonovo and G. E. Apostolakis, "A new importance measure for risk-informed decision making," Reliability Engineering \& System Safety, vol. 72, no. 2, pp. 193-212, 2001.

[54] A. C. F. Guimarães and C. M. F. Lapa, "Parametric fuzzy study for effects analysis of age on PWR containment cooling system," Applied Soft Computing, vol. 8, no. 4, pp. 1562-1571, 2008.

[55] A. Bobbio, L. Portinale, M. Minichino, and E. Ciancamerla, "Improving the analysis of dependable systems by mapping fault trees into Bayesian networks," Reliability Engineering \& System Safety, vol. 71, no. 3, pp. 249-260, 2001.

[56] X. Li, G. Chen, and H. Zhu, "Quantitative risk analysis on leakage failure of submarine oil and gas pipelines using Bayesian network," Process Safety and Environmental Protection, vol. 103, no. Part A, pp. 163-173, 2016.

[57] F. Yan and K. Xu, "A set pair analysis based layer of protection analysis and its application in quantitative risk assessment," Journal of Loss Prevention in the Process Industries, vol. 55, pp. 313-319, 2018.

[58] F. Yan, C. Jin, Z. Li, R. Cao, and K. Xu, "Research and development of field theory-based three-dimensional risk assessment. Part I: optimization of risk reduction," Safety Science, vol. 120, pp. 312-322, 2019.

[59] Orissa Renewable Energy Development Agency (OREDA), Offshore Reliability Data Handbook, OREDA, Trondheim, Norway, 4th edition, 2002. 